\title{
Low birth weight among adolescents at Cape Coast Metropolitan Hospital of Ghana
}

\author{
James Afriyie $^{1 *}$, Kweku Bedu-Addo², Ernest Amponsah Asiamah ${ }^{1}$, Solomon Twum Boateng ${ }^{1}$ \\ ${ }^{1}$ Department of Biomedical Sciences, University of Cape Coast, P.M.B Cape Coast, Ghana \\ ${ }^{2}$ Department of Physiology, School of Medical Sciences, Kwame Nkrumah University of Science and Technology \\ (KNUST), P.M.B, Kumasi, Ghana
}

Received: 24 September 2016

Accepted: 22 October 2016

\section{*Correspondence: \\ Mr. James Afriyie, \\ E-mail: jafriyie@ucc.edu.gh}

Copyright: ( ) the author(s), publisher and licensee Medip Academy. This is an open-access article distributed under the terms of the Creative Commons Attribution Non-Commercial License, which permits unrestricted non-commercial use, distribution, and reproduction in any medium, provided the original work is properly cited.

\section{ABSTRACT}

Background: Few studies have focused on low birth weight among adolescents. This study determines the incidence and factors associated with low birth weight (LBW) (weight at birth of less than 2,500 grams) among adolescents (aged $<20$ years) and how they differ from those in adult mothers (aged $\geq 20$ years).

Methods: The records of 768 deliveries at a hospital in Ghana from August 2014 to March 2015 were analyzed. Frequencies and percentages were generated. Bivariate relationships between maternal and neonatal characteristics and LBW were assessed using Chi-squared test. Multivariate logistic regression was used to evaluate the association between maternal age (being adolescent) and LBW. Odds ratios with $95 \%$ confidence interval were generated, and $\mathrm{p}$ $<0.05$ was considered significant.

Results: The incidence of LBW among adolescents was $14.3 \%$ and this was higher than the one among babies born to adult mothers $(14.3 \%$ vs. $7.4 \%, \mathrm{p}<0.013)$. Adolescent mothers were twice as likely to give birth to babies with LBW compared to adult mothers (OR 2.22; 95\% CI: 1.16 - 4.25). Preterm birth was significantly associated with LBW among adolescent and adult mothers.

Conclusions: Adolescents are at a higher risk of giving birth to babies of LBW than adults. Factors predicting LBW may not be different for adolescent and adult mothers. Interventions for prevention of negative sexual health outcomes should focus on adolescents.

Keywords: Adolescent, Cape coast, Low birth weight, Risk factors

\section{INTRODUCTION}

Adolescents are defined by the World Health Organization (WHO) as persons between the ages of 10 and 19 years. ${ }^{1}$ Such persons are maturing biologically and psychologically from childhood to assume adults roles, however, many adolescents are bearing children. The global birth rate among adolescents as indicated from the 2014 World Health Statistic is 49 per 1000 girls. ${ }^{2}$ According to the 2014 Ghana Demographic and Health Survey (GDHS), 14 percent of adolescents in Ghana started bearing children in that year. ${ }^{3}$ There are dangers associated with adolescent pregnancy and child bearing for the mother and child. Low birth weight (LBW), which was defined by WHO in 1992 as weight at birth of less than 2,500 grams, is more likely to occur among children born by adolescent mothers than adult mothers. In addition to LBW, preterm birth, asphyxia, and death during the first month of life are some of the complications that are more frequent among children of adolescent mothers. ${ }^{4,5}$

United Nations International Children's Emergency Fund (UNICEF) estimated that the incidence of LBW in 2013 was 16 percent globally, 14 percent for the West and Central Africa, and 6 percent for Central and Eastern Europe and the Commonwealth of Independent States (CEE/CIS). ${ }^{6}$ The incidence in the Africa region was very 
high as compared to the estimated figure for CEE/CIS. For Ghana, the estimated incidence of LBW was 11 percent.

Low birth weight is associated with neonatal death and future health problems. ${ }^{7}$ These include high risk of chronic diseases such as diabetes and cardiovascular diseases. ${ }^{8}$ Very low and extremely low birth weight children also show increased risk of growth retardation and delayed neurodevelopment. ${ }^{9}$ Several factors have been identified as causes or predictors of LBW. These include preterm birth (birth before 37 weeks of gestation), foetal growth retardation, and mothers in deprived socio-economic conditions, where mother's poor nutrition and health is the primary cause of $\mathrm{LBW}^{7}$

The Central Region of Ghana with Cape Coast as its capital has a good number of the great educational institutions as well as historical and tourist attraction sites. The region nonetheless, was ranked among the poor regions in the Country. ${ }^{10}$ According to the 2014 GDHS report, $21.3 \%$ of the women aged 15-19 years in the Central Region had begun bearing children and the region was one of three regions in Ghana whose teenagers tend to start child bearing earlier than others. ${ }^{3}$ Like other poor regions, LBW may be prevalent in Central Region of Ghana.

Several researches have been conducted on the prevalence and factors associated with LBW in different parts of Ghana with different results. The reported prevalence of LBW include $29.9 \%$ in Northern Region, $21.1 \%$ in a district in Ashanti Region, and $7.7 \%$ for Cape Coast. ${ }^{11-13}$ Factors found to be associated with LBW in the studies were sex of baby (female) and parity, antenatal or prenatal care, haemoglobin level, maternal anaemia, maternal age, residence, foetal infection, and period of gestation. ${ }^{11-13}$ These and many other studies have contributed in adding to the knowledge about LBW in Ghana and might have influenced policies in the country, but they focused on women in general and not on adolescents.

The purpose of this study was to determine the sociodemographic and neonatal factors that are associated with LBW among adolescents in Cape Coast. It also determined the incidence of LBW in the metropolis. The analysis also found out how the incidence and predictors of LBW among adolescents differ from those for adult women in the area. The study will add to literature on LBW in developing countries and influence adolescent health policies and practices in Ghana.

\section{METHODS}

\section{Study setting}

The Cape Metropolitan Hospital which records more than 100 monthly average deliveries was the site for the study. The hospital, established in 1939, is strategically located and now serves as a referral facility for inhabitants of Cape Coast and surrounding communities, with a population of 169,894 according to the 2010 Population and Housing census of Ghana. ${ }^{14}$

\section{Data collection}

The study was an analysis of maternal and neonatal data obtained from the Cape Coast Metropolitan Hospital, in Central Region of Ghana. The delivery records from August 2014 to March 2015 were compiled at the Maternal and Child Unit of the hospital from two delivery books containing maternal and neonatal information. We included only the deliveries for which we could retrieve complete information on birth weight and maternal age, giving us a total of 768 births within the period.

Maternal characteristics retrieved from the delivery books and categorized for the analyses were age in years (adolescent if less than 20 years or adult if more than 20 years), residential location (rural or urban), gravidity or number of pregnancies (primigravid or multigravid), and sulfadoxine-pyrimethamine (SP) dose (less than 2 doses or 2 or more doses). The neonatal characteristic retrieved for analyses were gestational age in weeks which was measured using pelvic scan (classified as preterm if it was less than 37 weeks or term if it was at least 37 weeks). Other characteristics were sex (female or male), multiple birth (yes or no), delivery presentation (breech birth or cephalic), and birth weight in kilogramme $(\mathrm{kg})$. Birth weight was the outcome variable in the study. The birth weights were measured using standardized weighing scale and were classified into two as low birth weight (less than $2.5 \mathrm{~kg}$ ) and normal birth weight $(2.5 \mathrm{~kg}$ or more). Approval for this population level study, an analysis of a secondary data, was given by the Research Committee of the Department of Biomedical Sciences, University of Cape Coast, Ghana. We also obtained permission from the Cape Coast Metropolitan Hospital to use the records for the study.

\section{Statistical analyses}

The data were analyzed with SPSS, version 20. Descriptive statistics of the maternal and neonatal characteristics were performed to obtain their frequencies and percentages. Using independent-sample $\mathbf{t}$ tests, the mean birth weight of children of adolescent mothers (aged less than 20 years) was compared with that of adult mothers (20 years and above). Proportions of categorical variables between adolescent and adult mothers were also compared. Bivariate relations between maternal and neonatal characteristics and LBW were examined using Chi-squared test. Multivariable logistic regression analysis was performed to evaluate the association between maternal age (being adolescent) and LBW, as adjusted for other variables. We entered variables that showed statistical significant association at $p<0.05$ with $\mathrm{LBW}$ in bivariate analyses into the multivariate analyses. 
Crude and adjusted odds ratios with 95\% confidence interval $(\mathrm{CI})$ were generated. Association and differences between variables were considered significant if $p<0.05$.

\section{RESULTS}

Out of the 768 deliveries included in the study, 119 were from adolescent mothers and thus (119/768) 15.49\% of the births were from adolescents mothers. Among the adolescents, $78.8 \%$ were primigravid (were pregnant for the first time) and the average age at first delivery among the adolescents was $17.25 \pm 1.442$ years. The mean age of the adolescent mothers was $17.95 \pm 1.14$ years. The mean birth weight for babies was $2.92 \pm 0.47 \mathrm{~kg}$ for adolescent mothers, $3.16 \pm 0.54 \mathrm{~kg}$ for adult mothers, and $3.12 \pm 0.54$ $\mathrm{kg}$ for all mothers in the study. The mean birth weight for babies of adolescent mothers was slightly lower than that for adult mothers $(2.92 \pm 0.47 \mathrm{~kg}$ vs. $3.16 \pm 0.54 \mathrm{~kg}$; $\mathrm{p}=0.000)$.

Comparisons of characteristics between adolescent and adult mothers are provided in Table 1. Adolescent mothers were more likely to be primigravid $(78.8 \%$ vs. $18.2 \% ; \mathrm{p}=0.000)$ and to have single births $(100.0 \%$, vs. $93.7 \% ; \mathrm{p}=0.005)$ than adult mothers. They were however less likely than adult mothers to have taken 2 or more doses of sulfadoxine-pyrimethamine (87.3\% vs. $94.3 \%$; $\mathrm{p}=0.031)$. Compared to adult mothers, adolescent mothers were not at higher risk of breech birth and there was no significant difference between adolescent and adult mothers in terms of residential location and sex of baby.

Table 1: Maternal and neonatal characteristics, by age of mother.

\begin{tabular}{|c|c|c|c|c|}
\hline \multirow{3}{*}{ Characteristics } & \multicolumn{3}{|l|}{ Mothers } & \multirow{3}{*}{ P - value } \\
\hline & Adolescent $(<20$ years $)$ & Adult ( $\geq 20$ years) & All (All ages) & \\
\hline & No of Participants (\%) & No of Participants (\%) & No of Participants (\%) & \\
\hline \multicolumn{5}{|l|}{ Low Birth Weight } \\
\hline Yes & $17(14.3)$ & $48(7.4)$ & $65(8.5)$ & \multirow{2}{*}{0.013} \\
\hline No & $102(85.7)$ & 601 ( 92.6) & $703(91.5)$ & \\
\hline \multicolumn{5}{|c|}{ Residential Location } \\
\hline Rural & $33(29.5)$ & $175(29.0)$ & $208(29.1)$ & \multirow{2}{*}{0.916} \\
\hline Urban & $79(70.5)$ & $429(71.0)$ & $508(70.9)$ & \\
\hline \multicolumn{5}{|l|}{ Gravidity } \\
\hline Primigravid & $93(78.8)$ & $117(18.2)$ & $210(27.6)$ & \multirow{2}{*}{0.000} \\
\hline Multigravid & $25(212)$ & $526(81.8)$ & $551(72.4)$ & \\
\hline \multicolumn{5}{|c|}{ Labour Complication } \\
\hline Yes & $3(2.5)$ & $43(6.8)$ & $46(6.1)$ & \multirow{2}{*}{0.079} \\
\hline No & $115(97.5)$ & $594(93.2)$ & 709 (93.9) & \\
\hline \multicolumn{5}{|l|}{ SP Dose } \\
\hline Less than 2 & $9(12.7)$ & $23(5.7)$ & $32(6.8)$ & \multirow{2}{*}{0.031} \\
\hline 2 or more & $62(87.3)$ & $379(94.3)$ & $441(93.2)$ & \\
\hline \multicolumn{5}{|c|}{ Delivery Presentation } \\
\hline Breech & $2(1.7)$ & $25(3.9)$ & $27(3.6)$ & \multirow{2}{*}{0.239} \\
\hline Cephalic & $115(98.3)$ & $615(96.1)$ & $730(96.4)$ & \\
\hline \multicolumn{5}{|l|}{ Multiple Birth } \\
\hline Yes & $0(0.00)$ & $41(6.3)$ & $41(5.3)$ & \multirow[t]{2}{*}{0.005} \\
\hline No & $119(100.00)$ & $608(93.7)$ & $727(94.7)$ & \\
\hline \multicolumn{5}{|l|}{ Child's Sex } \\
\hline Female & $64(53.8)$ & $312(48.1)$ & $376(49.0)$ & \multirow{2}{*}{0.252} \\
\hline Male & $55(46.2)$ & $337(51.9)$ & $392(51.0)$ & \\
\hline
\end{tabular}

Abbreviation: SP, Sulfadoxine-Pyrimethamine

Table 2: Association between maternal age and low birth weight in bivariate and multivariate analyses.

\begin{tabular}{|c|c|c|c|c|c|c|}
\hline & $\begin{array}{l}\text { Low birth } \\
\text { weight N }(\%)\end{array}$ & $\begin{array}{l}\text { Normal birth } \\
\text { weight N }(\%)\end{array}$ & $\begin{array}{l}\text { Crude odds } \\
\text { ratio }(95 \% \mathrm{CI})\end{array}$ & $\begin{array}{l}\text { P- } \\
\text { value }\end{array}$ & $\begin{array}{l}\text { Adjusted odds ratio* } \\
\text { [aOR] (95\% CI) }\end{array}$ & $\begin{array}{l}\text { P- } \\
\text { value }\end{array}$ \\
\hline Maternal age & & & \multirow[b]{2}{*}{$2.09(1.16-3.77)$} & \multirow[b]{2}{*}{0.015} & \multirow[b]{2}{*}{$2.22(1.16-4.25)$} & \multirow[b]{2}{*}{0.017} \\
\hline $\begin{array}{l}<20 \text { years (adolescent) } \\
\geq 20 \text { years (adult) }\end{array}$ & $\begin{array}{l}17(26.2) \\
48(73.8)\end{array}$ & $\begin{array}{l}102(14.5) \\
600(85.5)\end{array}$ & & & & \\
\hline
\end{tabular}

Abbreviation: SP, Sulfadoxine- Pyrimethamine; CI, Confident Interval

* Adjusted for preterm birth, breech birth, and multiple birth

The incidence of LBW among adolescents was $14.3 \%$ and this was higher than the one among babies born to adult (older) mothers (14.3\% vs. $7.4 \%, \mathrm{p}=0.013)$ (Table 1). Of all the 768 deliveries included in the study, 65 had 
low birth weight, giving a LBW incidence of $8.5 \%$ among all the women in the study.

In bivariate analyses, maternal age (being adolescent) was significantly associated with the likelihood of giving birth to a child of LBW. In multivariate analyses, after adjusting for other factors which showed significant association with LBW in bivariate analyses, the association remained statistically significant (Table 2). Adolescent mothers were twice as likely to give birth to children with low birth weight compared to adult mothers (OR 2.22; 95\% CI:1.16- 4.25).

Results of the analyses showing the association between LBW and maternal and neonatal characteristics are provided in Table 3. Among adolescents, preterm birth $(\mathrm{p}=0.043$ ) was the only factor found to be associated low birth weight. Preterm birth was also significantly associated with low birth weight among adults $(\mathrm{p}=0.000)$. Absence of cases for multiple births among adolescent mothers did not permit comparison with adult mothers. Residential location (rural or urban), gravidity (primigravid or multigravid), sulfadoxine-pyrimethamine (SP) dose (less than 2 or 2 or more doses), delivery presentation (breech birth or cephalic), and sex of baby (female or male) did not show significant association with low birth weight among adolescent or adult mothers in this study. Breech birth was however significantly associated with low birth weight among all the women $(\mathrm{p}=0.046)$.

Table 3: Bivariate analyses showing factors associated with low birth weight in adolescent and adult mothers.

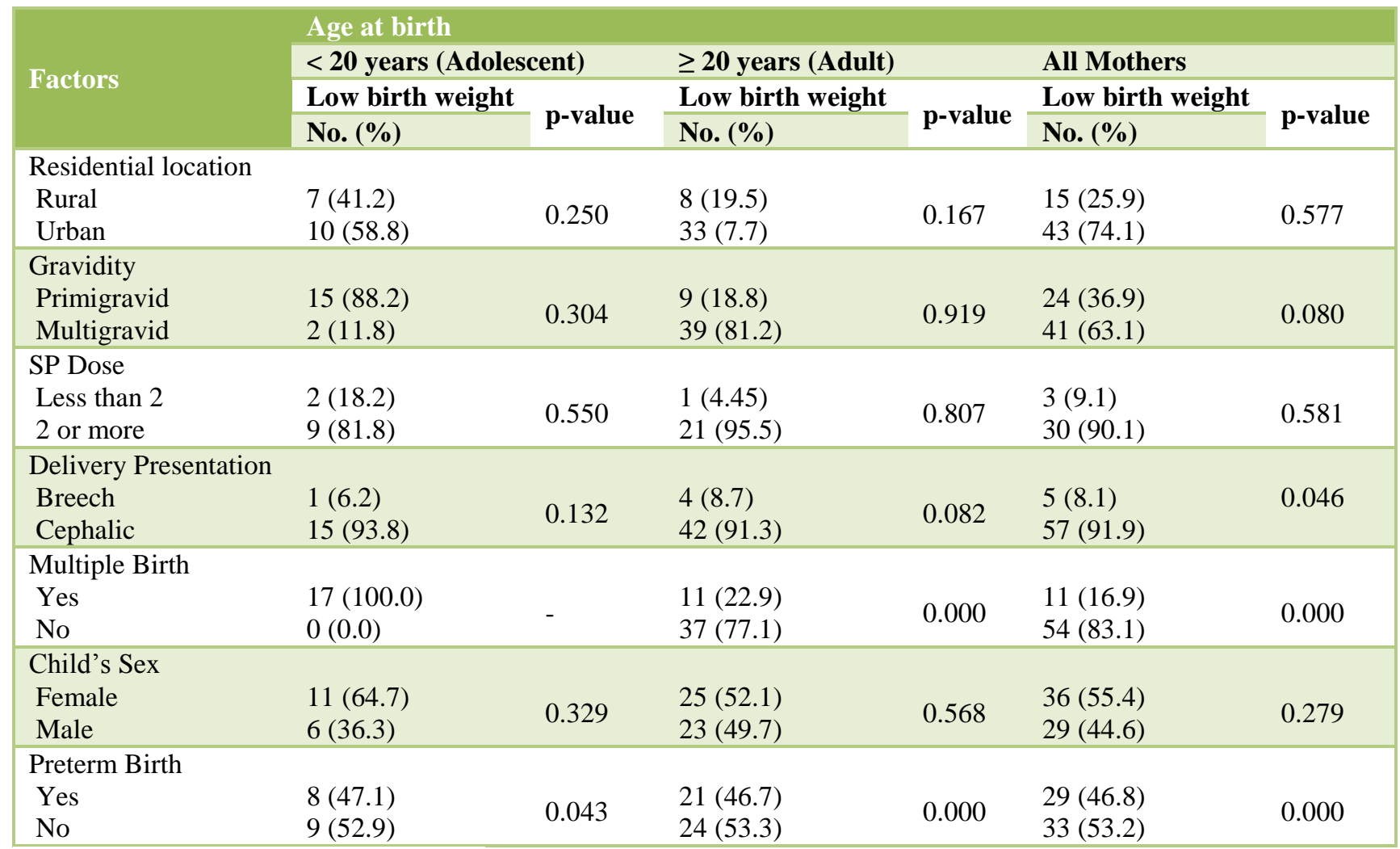

Abbreviation: SP, Sulfadoxine-Pyrimethamine

\section{DISCUSSION}

The proportion of deliveries due to adolescents $(15.5 \%)$ in this study was lower than the one for the whole country. It was reported that $30 \%$ of all the registered births in 2014 in Ghana was from adolescents. ${ }^{15}$ The differences may be due to the challenges of birth registration in Ghana where more than 4 in 10 children are not registered at birth. ${ }^{16}$ Probably more adult than adolescent parents did not get their children registered in 2014.
The finding of this study that shows that babies of adolescents generally have birth weights lower than those of babies of their adult counterparts has been established in other studies. This study found a significantly higher proportion of LBW among adolescent than adult mothers with adolescent mothers being twice more likely to give birth to children with LBW than adult mothers. In a similar study, in United States and with a larger sample size, distribution of low birth weight was however equal between adolescent and young adult mothers. ${ }^{17}$ Another study also concluded that adolescence was a risk factor 
for LBW only for mothers without partners. ${ }^{18}$ The result of this study however confirms earlier ones that suggest that adolescent pregnancy or younger age at delivery is a risk factor for LBW. ${ }^{13,19}$ The younger age of teenagers in Cape Coast, coupled with lack of social support and poverty might have prevented them from starting prenatal care early. ${ }^{20}$ It is also possible that adolescents in the study were not practicing healthy eating habits. ${ }^{21}$ The higher proportion of LBW babies among adolescents might have also been caused by poor prenatal care as well as poor socio-economic and nutritional status of the adolescent mothers. Adolescent mothers usually have poor socioeconomic and reproductive conditions, which give them a higher risk of giving birth to LBW children than women of older ages. ${ }^{18}$

The significant association between preterm birth and LBW recorded in this study was not unique to adolescent mothers. In adult and all mothers, preterm birth was also associated with the likelihood of giving birth to LBW babies. This result agrees with documented studies that shorter periods of gestation or preterm delivery was associated with LBW. ${ }^{13,22}$ Maybe, the neonates born prematurely did not get enough time to achieve normal weight.

In the study, living in rural areas was not a risk factor for giving birth to babies with LBW even though it was shown to be a risk factor by an earlier study in northern Ghana. $^{11}$ In that study, higher proportions of LBW in rural areas was attributed to poorer access to health and socio-economic differences. In Central Region, urban dwellers may have better access to health service than rural dwellers, but not much difference exist between the proportion of rural and urban dwellers using health services. Again, the differences in socio-economic characteristics between urban and rural areas are not marked in Cape Coast. These may explain why residential location was not associated with low birth weight in this study.

The results of this study showing that being a female newborn is not a risk factor for LBW has also been reported in earlier studies, even though other studies have reported the opposite. ${ }^{11,13,22,23}$ The association between multiple birth and low birth weight has been established but this analysis could not determine it for lack of statistics. Being primigravid was not associated with higher risk of LBW among adolescents in this study and this was at variance with the results of a study in United States. ${ }^{17}$ This difference in results may be due to the comparatively smaller sample size of this study. Sulfadoxine-pyrimethamine (SP) given to prevent adverse consequences of malaria did not show significant association with LBW in this study. This corroborates with other works that reported that 2 or more doses of SP were not significantly associated with LBW. ${ }^{24}$ Breech presentation has not been established in earlier literature as a risk factor for low birth weight among adolescents just as what this study suggests. The observed association between breech presentation and low birth weight in all the mothers in the study ( $\mathrm{p}=0.046$ ) needs to be interpreted with some caution as the presence of an association does not mean causation.

Prenatal care, maternal anaemia, maternal height, and marital status have been documented as factors associated with LBW. ${ }^{13,17,22}$ The association between these factors and LBW could not however be determined in this study. This was because the delivery books used for this study did not capture data on these factors and this was one of the limitations of the study. Another limitation was that we excluded a number of deliveries which could have increased the sample size and the chance of finding significant differences, which might have been missed by the small sample size of the study. The exclusion was necessary because there were some irregularities in the data in the two different delivery books used.

Future research, using more rigorous study design and collecting primary data from mothers will help address how socio demographic and neonatal characteristics affect low birth weight among adolescents in Ghana.

\section{CONCLUSION}

The findings of this analysis suggest that adolescents are at a higher risk of giving birth to babies of low birth weight as compared to adult mothers, as adolescents in general tend to have more risky behaviours and poorer socio demographic characteristics than adults. However, the factors predicting low birth weight may not be different for adolescents and adult mothers. Cape Coast Metropolitan Hospital serves as a referral facility for the metropolis; hence the results of the study can be generalized to all adolescents in Cape Coast.

Pregnancy prevention and other sexual health interventions of government and nongovernmental organizations in Cape Coast and Central Region should keep their focus on adolescents who are at higher risk of sexual behaviours and outcomes.

\section{Funding: No funding sources}

Conflict of interest: None declared

Ethical approval: Approval for this population level study which was an analysis of a secondary data was given by the Research Committee of the Department of Biomedical Sciences, University of Cape Coast, Ghana. We also obtained permission from the Cape Coast Metropolitan Hospital to use the records for the study

\section{REFERENCES}

1. World Health Organization. Health Topics. Adolescent Health. 2016. http://www.who.int/topics/adolescent_health/en/

2. World Health Organization. WHO Medical Center. Adolescent Pregnancy. 2014. http://www.who.int/mediacentre/factsheets/fs364/en/ 
3. Ghana Statistical Service. Ghana Demographic and Health Survey 2014: Key Indicators. 2015.

4. WHO. ICD-10 Transition. Fam Pract Manag. 2011;18:39. Available from: http://www.ncbi.nlm.nih.gov/pubmed/22184833

5. World Health Organization. Maternal, newborn, child and adolescent health. Adolescent Pregnancy. 2016.

http://www.who.int/maternal_child_adolescent/topic s/maternal/adolescent_pregnancy/en/

6. United Nations Children's Fund and World Health Organization. Unicef Global Database: Low birth weight: percentage of infants weighing less than 2,500 grams at birth. 2014.

7. United Nations Children's Fund and World Health Organization. Low Birthweight: Country, regional and global estimates. Unicef. 2004:1-31.

8. Risnes KR, Vatten LJ, Baker JL, Jameson K, Sovio U, Kajantie E. Birthweight and mortality in adulthood: A systematic review and meta-analysis. Int J Epidemiol. 2011;40(3):647-61.

9. Tchamo M, Prista A, Leandro C. Low birth weight, very low birth weight and extremely low birth weight in African children aged between 0 and 5 years old: a systematic review. J Dev Orig Heal Dis. 2016;7(4):408-15.

10. Ghana Statistical Service. Living Standards Survey Round 6. (GLSS 6): Poverty profile in Ghana (2005 2013). 2014.

11. Abubakari A, Kynast-Wolf G, Jahn A. Prevalence of abnormal birth weight and related factors in Northern region, Ghana. BMC Pregnancy Childbirth. 2015;15(1):1-8. Available from: http://dx.doi.org/10.1186/s12884-015-0790-y

12. Ofori MF, Abdul-rahaman I, Yekeen R. Maternal Risk Factors for Low Birth Weight in a District Hospital in Ashanti Region of Ghana. Res Obstet Gynecol. 2013;2(4):48-54.

13. Prah J, Ameyaw EO, Afoakwah R, Kudom A. Factors affecting birth weight in Cape Coast, Ghana. 2016;5(5):1536-9.

14. Ghana Statistical Service. 2010 Population and housing census: Final results. Ghana Stat Serv Final results. 2012;11.

15. Coughlin J. Teenage pregnancy in Ghana: Assessing situation and moving forward. Graphic Online. 2016. http://www.graphic.com.gh/news/generalnews/teenage-pregnancy-in-ghana-assessingsituation-and-moving-forward.html
16. United Nations Children's Fund and World Health Organization. Launch of Ghana's new automated birth registration system; making registration of children smart, quick and reliable. UNICEF Ghana. Unicef. 2016.

17. Harville EW, Madkour AS, Xie Y. Predictors of birth weight and gestational age among adolescents. Am J Epidemiol. 2012;176(7):150-63.

18. Guimarães AM, Bettiol H, Souza L, Gurgel RQ, Almeida ML, Ribeiro ER. Is adolescent pregnancy a risk factor for low birth weight? Rev Saude Publica. 2013;47(1):11-9.

19. Okosun IS, Halbach SM, Dent MM, Cooper RS. Ethnic Differences in the Rates of Low Birth Weight Attributable to Differences in Early Motherhood: A study from the Third National Health and Nutrition Examination Survey. J Perinatol. 2000;105-9.

20. Yeboah MK. Social Support and Access To Prenatal Health Services : a Study of Pregnant Teenagers in Cape Coast, Ghana. J Sci Technol. 2012;32(1):6878.

21. Buxton CNA. Ghanaian Junior High School Adolescents Dietary Practices and Food Preferences: Implications for Public Health Concern. J Nutr Food Sci. 2014;4(5):1-9.

22. Oladeinde HB, Oladeinde OB, Omoregie R, Onifade AA. Prevalence and determinants of low birth weight: the situation in a traditional birth home in Benin City, Nigeria. Afr Health Sci. 2015;15(4):1123-9.

23. Nketiah-Amponsah E, Abuosi A, Arthur E. Maternal Socio-Economic Status and Childhood Birth Weight: A Health Survey in Ghana. Neonatal Care. 2012. Available from: https://www.educationnest.com/components/com_js hopping/files/files_products/PDF_files/MEDICINEP DF/Neonatal_Care.pdf\#page $=11$

24. Arinaitwe E, Ades V, Walakira A, Ninsiima B, Mugagga O, Patil TS, et al. Intermittent Preventive Therapy with Sulfadoxine-Pyrimethamine for Malaria in Pregnancy: A Cross-Sectional Study from Tororo, Uganda. PLoS One. 2013;8(9):6-11.

Cite this article as: Afriyie $\mathrm{J}$, Bedu-Addo K, Asiamah EA, Boateng T. Low Birth weight among adolescents at Cape Coast Metropolitan Hospital of Ghana. Int J Reprod Contracept Obstet Gynecol 2016;5:4242-7. 